\title{
Research on IEET Education Certification in Taiwan
}

\author{
Xing Yi \\ Xiamen University of Technology, Xiamen, China, 361005
}

Keywords: IEET; Education; Certification

Abstract: In a short period of two years, Taiwan's educational and engineering circles have rapidly established an authoritative and independent accreditation institution for engineering education, the Taiwan Institute of Engineering Education, and established an international accreditation system for engineering specialty, and become a temporary member of the Washington Agreement. Faced with the rapid development of engineering education certification in Taiwan, the mainland should establish authoritative certification bodies as soon as possible, design certification procedures and standards in accordance with international practices, actively integrate with international standards, and strive to achieve international recognition of engineering education quality.

In recent years, as an important measure to guarantee the quality of higher engineering education, it realizes the mutual recognition of education level and vocational qualification, engineering education professional certification has attracted more and more attention of researchers and institutions in China, and has a certain degree of practice and development. However, the progress of Engineering Education Accreditation in China's mainland is still very slow compared with that in Britain, the United States, Hong Kong, China, Germany, Korea and Japan, which have already established engineering education accreditation system but are still seeking its perfection and development, or with Germany, Korea and Japan, which have just started Engineering Education Accreditation in recent years and are actively realizing international accreditation. It is not conducive to the transnational trade of engineering business in mainland China and the flow of engineering technicians around the world. It is also difficult to meet the needs of economic globalization and internationalization of higher education.

\section{Overview of engineering education certification and ieet development in Taiwan}

The development of Engineering Education Accreditation in Taiwan began in January 2003. The President Forum of Taiwan's Educational Administration Department instructed the working group to promote the accreditation and the establishment of the Institute of Engineering Educational Taiwan (IEET) in June of the same year.

IEET is a non-official and non-profit social organization with independent legal person. It is a window of international communication for engineering education certification in Taiwan, which is entrusted by the administrative department of education in Taiwan. The development process is shown in Table 1. 
Table 1.The development process

\begin{tabular}{|l|l|}
\hline & The development process \\
\hline 2004.04 & IEET promulgated the Accreditation Criteria \\
\hline 2004.08 & $\begin{array}{l}\text { IEET formally launched the certification of Engineering education, } \\
\text { which is EAC certification. }\end{array}$ \\
\hline 2007.06 & After becoming a full member of the Washington Accord \\
\hline 2009.06 & it joined the Seoul Accord \\
\hline 2012.06 & it joined the Sydney Accord \\
\hline 2016.06 & it joined the Canberra Accord \\
\hline
\end{tabular}

It has become the most influential formal or associate member of the four global engineering education certification agreements.

At present, IEET consists of Engineering Accreditation Commission (EAC), Computing Accreditation Commission (CAC), Technology Accreditation Commission (TAC/AC-AD) and Construction Education Accreditation Executive Committee. Architectural Accreditation Commission (AAC) and Design Accreditation Commission (DAC) are five accreditation executive committees, which implement engineering education certification (EAC certification or EAC), information education certification (CAC certification or CAC), technical education certification (TAC/AC-AD certification or TAC/AC-AD). International certification and design education certification (DAC certification or DAC) in the four major fields of Engineering education, such as Architectural Accreditation Commission (AAC certification or AAC), have covered the whole higher engineering education from associate degree (associate degree), undergraduate (bachelor's degree) to postgraduate education (master's degree and doctor's degree). Bit level.

Since 2004, 50\% of universities and 80\% of Engineering Education Majors in Taiwan have participated in IEET certification. A total of 1451 majors in 561 departments have passed IEET certification. The development of engineering education certification in Taiwan not only promotes the integration of Engineering Education in Taiwan with international standards, methods and technologies, but also has a certain impact on Southeast Asia and the mainland.

IEET tutored PTC of Philippines to become a member of WA in 2012-2013; tutored MENGC of Myanmar to establish engineering education certification mechanism from 2013 to now; invited by Higher Education Department of Iguanodon Provincial Education Department in April and October 2016 to conduct engineering education tutoring for vice-president of teaching, Dean of educational affairs and top-ranking higher vocational colleges, respectively. In July, the cooperation model was discussed with Iguanodon Province, and announced in December. The first batch of undergraduate education majors in engineering education in 8 universities accredited by IEET in Iguanodon Province and 26 applications for accreditation of Engineering Education Majors in 12 Higher Vocational Colleges and universities; the accreditation of medical electronic instruments and maintenance majors in Shanghai Medical College of Health in May 2016; and the environmental workers in the first batch of 8 Universities in Fijian Province such as Fuzhou University in September 2016. Cheng and other 14 undergraduate majors implemented EAC certification, and the second batch of professional certification counseling started in October.

\section{Organizational structure}

The Taiwan Institute of Engineering Education has established committees, permanent offices and other institutions, and has employed several full-time personnel. There are now more than 200 individual members and more than 20 group members (academies and academic units). The organization of the whole society is shown in Figure 1. 


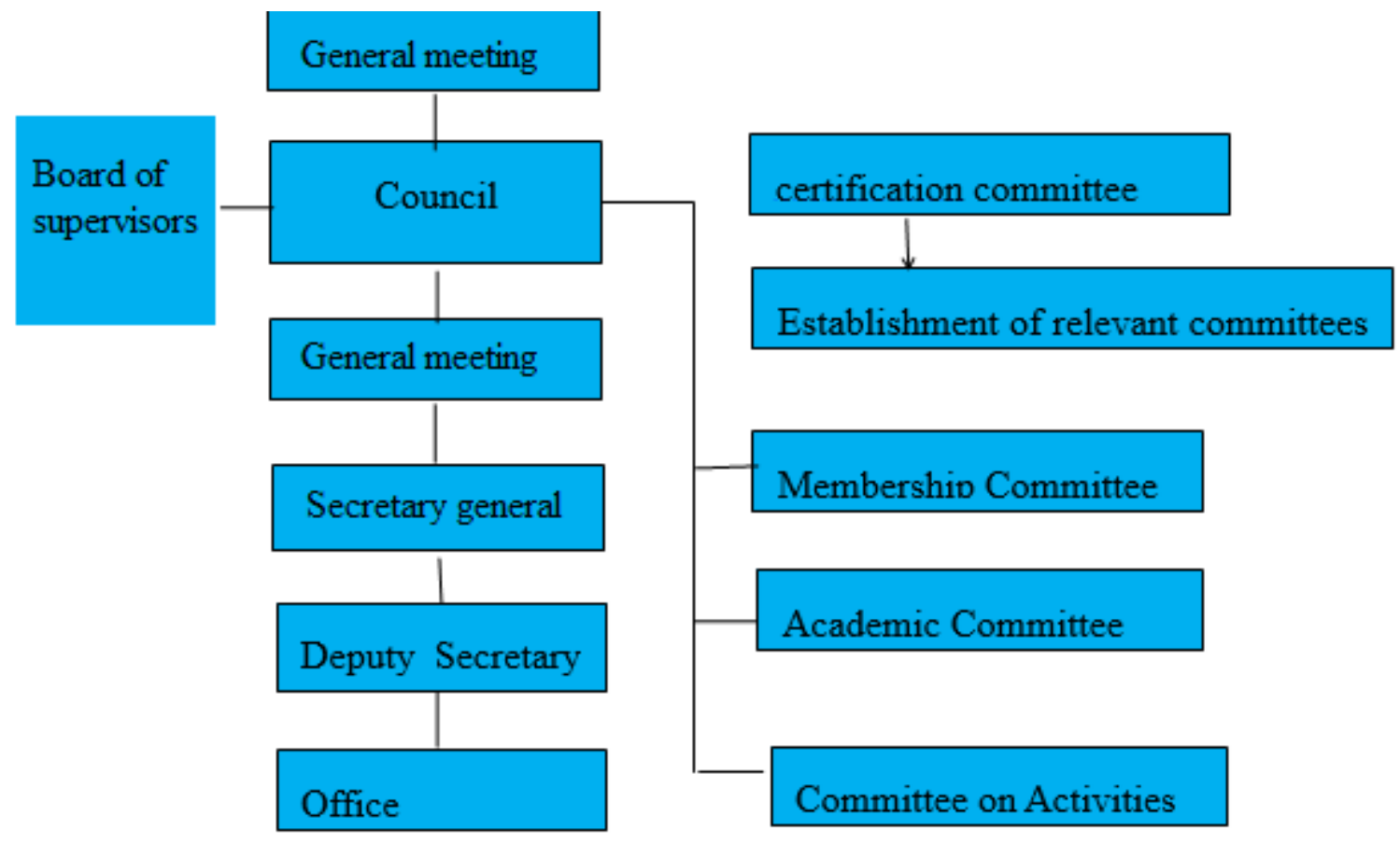

Figure 1 Organizational structure

Among them, the Accreditation Committee under the Council is responsible for the accreditation work. The whole work and all activities of the committee are under the direct supervision and leadership of the council. According to international practice, the Accreditation Committee is divided into the accreditation executive committee, the appeal committee and the executive director's office (the organizational structure of the Accreditation Committee is shown in figure 2).

Among them, the certification standards group under the Executive Director's Office is responsible for the formulation of certification standards, the International Affairs Group is responsible for international affairs, and the General Service Group is responsible for domestic affairs. The Engineering Education Accreditation Executive Committee (EAC), the Science and Technology Education Accreditation Executive Committee (TAC) and other accreditation executive committees under the Accreditation Executive Committee are responsible for specific matters related to professional accreditation. The Appeals Board and the Accreditation Executive Committee are at the same level and are responsible for accepting complaints from various units about the accreditation process and results. There is a close relationship between the Accreditation Executive Committee and the Executive Directorate through accreditation standards and international and domestic affairs.

The whole authentication process takes about a year. The validity period of the certification is up to six years, and it should be reviewed after the expiration of the validity period. The Taiwanese Institute of Engineering adopts peer-to-peer evaluation method for evaluation. The members of the expert group for field visits are recommended by the relevant professional accreditation executive committee, including one chairman, two to four experts and one secretary. The specialty composition of the expert group is in accordance with the situation of the accredited departments as far as possible, mainly the deans, Department directors, senior professors and renowned persons in the engineering industry of various colleges and universities. In terms of accreditation standards, the Taiwan Institute of Engineering Education convened relevant experts and published the first Accreditation Criteria 2004 (AC2004) in 2004, which lasted half a year.

AC2004 adopts the current internationally popular "results-oriented" certification ideas. The 
certification standards mainly include eight items, such as educational objectives, students, educational effectiveness and evaluation, curriculum and its composition, teachers, equipment and space, administrative support funds and department certification standards. AC2004 also has an explanatory edition to increase its readability and facilitate the understanding of various engineering departments. In the process of accreditation, they emphasize that AC2004 is only the lowest standard. They emphasize that the purpose of accreditation is to promote the continuous improvement of the quality of Engineering faculties, help engineering faculties to establish a spontaneous self-inspection mechanism, help engineering faculties to find their own accurate positioning, and emphasize that accredited faculties should focus on denuclearizing and keep track of graduates' status. As well as the response of the industry and employers and flexibly adjust their own training programs according to these information.

\section{Enlightenment to the Establishment of Higher Engineering Education Certification System in Mainland China}

In just two years, the Taiwan Institute of Engineering Education has been a temporary member of the Washington Agreement. In mainland China, engineering education certification has been introduced and advocated since 1980s, but no substantial progress has been made up to now. Although this is due to the complexity of the engineering education system in mainland China and many other reasons, it is not closely related to our working methods. According to the Washington Agreement, temporary members can apply for full membership in two years. After becoming a full member, we have the "one vote veto" to decide whether other temporary members can become full members. This will certainly have a certain impact on the participation of civil engineering education accreditation agencies in international exchanges and mutual recognition.

At present, whether from the needs of the development of Engineering Education in mainland China or from the international environment, we are required to strengthen the construction of higher engineering education certification system. For this reason, the Enlightenment of Taiwan Institute of Engineering Education has its main point, which is establishing an authoritative certification institution as soon as possible and ensuring its independence and authoritative organization work successfully. When establishing the certification system, any country or region takes the establishment of corresponding organizations as the beginning and foundation of its work. The main reason why the exploration and practice of engineering certification in mainland China has not formed a certain scale and system in recent years is that there has been no authoritative organization to organize and coordinate this work.

\section{Conclusion}

"Serious" cultural construction of "certification" is one of the basic experiences of the healthy and sustainable development of IEET certification in Taiwan for 12 years. To develop engineering education certification in mainland China, it is necessary to strengthen the construction of "serious" engineering education and its "certification" culture, to truly "say" the standard of engineering education certification, to conscientiously "do" the "say" bit by bit, and to realize "certification" in an all-round way, not only to cultivate students, but also to cultivate high-level engineering and technical personnel. The dual goal of "earnestly" running a school in engineering education colleges and universities. To strengthen the construction of "earnest" Engineering Education Culture in an all-round way should become a common understanding of realizing the healthy and sustainable development of engineering education and its certification in mainland China. 


\section{References}

[1] Din Ch eng. Review of Taiwan's "University Evaluation Method" and Department Evaluation [J]. Exploration of Higher Education, 2008 (3).

[2] Li Man jun. The effect of engineering and science and technology education certification on international conformity [J]. Evaluation, 2008 (14).

[3] Thomas Friedman. The world is flat. Changsha: Human Science and Technology Press [M], 2006.

[4] Lang Iffy, Wang Haiphong. New Exploration of Performance Evaluation Principles and Indicators [J]. Learning and Exploration, 2008, (6).

[5] Lu Hinayana and Duo Deng.

Construction of the Performance Evaluation Index System for Secondary Colleges of Universities [J]. Journal of the State Administration College, 2008, (7). 